\title{
Nestin-expressing vascular wall cells drive development of pulmonary hypertension
}

\author{
Farhan Saboor ${ }^{1,6}$, Ansgar N. Reckmann ${ }^{1,6}$, Claudia U.M. Tomczyk ${ }^{1,6}$, \\ Dorothea M. Peters ${ }^{2}$, Norbert Weissmann ${ }^{2}$, Andre Kaschtanow ${ }^{1}$, \\ Ralph T. Schermuly², Tatyana V. Michurina ${ }^{3,4,5}$, Grigori Enikolopov ${ }^{3,4,5}$, \\ Dieter Müller ${ }^{1}$, Andrea Mietens ${ }^{1}$ and Ralf Middendorff ${ }^{1}$
}

\begin{abstract}
Affiliations: 'Institute of Anatomy and Cell Biology, Justus-Liebig-University, Giessen, Germany. ${ }^{2}$ University of Giessen and Marburg Lung Center (UGMLC), Excellence Cluster Cardio-Pulmonary Systems (ECCPS), Dept of Internal Medicine, Members of the German Center for Lung Research, Justus-Liebig-University, Giessen, Germany. ${ }^{3}$ Cold Spring Harbor Laboratory, Cold Spring Harbor, NY, USA. ${ }^{4}$ Center for Developmental Genetics and Department of Anesthesiology, Stony Brook University, Stony Brook, NY, USA. ${ }^{5}$ NBIC, Moscow Institute of Physics and Technology, Moscow, Russia. ${ }^{6}$ These authors contributed equally.
\end{abstract}

Correspondence: Ralf Middendorff, Institute of Anatomy and Cell Biology, Justus-Liebig-University Giessen, Aulweg 123, 35385 Giessen, Germany. E-mail: ralf.middendorffdanatomie.med.uni-giessen.de

ABSTRACT Nestin, a well-known marker of neuronal stem cells, was recently suggested to characterise stem cell-like progenitors in non-neuronal structures during development and tissue repair. Integrating novel morphological approaches (CLARITY), we investigate whether nestin expression defines the proliferating cell population that essentially drives vascular remodelling during development of pulmonary hypertension.

The role of nestin was investigated in lungs of nestin-GFP (green fluorescent protein) mice, models of pulmonary hypertension (rat: monocrotaline, SU5416/hypoxia; mouse: hypoxia), samples from pulmonary hypertension patients and human pulmonary vascular smooth muscle cells (VSMCs).

Nestin was solely found in lung vasculature and localised to proliferating VSMCs, but not bronchial smooth muscle cells. Nestin was shown to affect cell number and was significantly enhanced in lungs early during development of pulmonary hypertension, correlating well with increased VSMC proliferation, expression of phosphorylated (activated) platelet-derived growth factor receptor $\beta$ and downregulation of the smooth muscle cell differentiation marker calponin. At later time points when pulmonary hypertension became clinically evident, nestin expression and proliferation returned to control levels. Increase of nestin-positive VSMCs was also found in human pulmonary hypertension, both in vessel media and neointima.

Nestin expression seems to be obligatory for VSMC proliferation, and specifies lung vascular wall cells that drive remodelling and (re-)generation. Our data promise novel diagnostic tools and therapeutic targets for pulmonary hypertension.

@ERSpublications

In lung, nestin is solely found in vascular smooth muscle cells and drives remodelling in pulmonary hypertension http://ow.ly/StPCS

This article has supplementary material available from erj.ersjournals.com

Received: April 112015 | Accepted after revision: Sept 172015 | First published online: Dec 232015

Support statement: DFG, Excellence Cluster Cardio Pulmonary System, LOEWE Programme of the State of Hesse, BMBF, German Lung Center; University Medical Center Giessen and Marburg (UKGM, Research Grant); NIMH, NIA R01AG040209, NYSTEM C029569, Ministry of Education and Science of the Russian Federation 11G34.31.0071. Funding information for this article has been deposited with FundRef.

Conflict of interest: None declared.

Copyright OERS 2016 


\section{Introduction}

Nestin is a class VI intermediate filament. It was first found in neuronal stem cells [1], although nestin expression has been described in progenitor cells of other organs during development and in adult tissue during repair, as reviewed by WIESE et al. [2]. Nestin-expressing cells from different tissues were assigned characteristics similar to stem cells [2].

Only a few previous studies localised nestin to vascular wall cells, which include vascular smooth muscle cells (VSMCs) and pericytes [3-6]. We demonstrated nestin ${ }^{+}$VSMCs and pericytes as progenitors of testosterone-producing Leydig cells [4], and their clonogenic self-renewal as well as their differentiation into neural and mesenchymal cell lineages was described recently [7].

Resident progenitor cells have been described in different cell populations of the lung [8,9], but studies on the expression, localisation and function of nestin in the lung, during both development and repair, were only recently started by us and others [10-12]. In the adult lung, structural alterations are found under various pathological conditions, e.g. pulmonary hypertension, where remodelling of the vasculature predominates. In pulmonary hypertension, vasoconstriction, thrombosis and remodelling can be found as the pathological triad in the resistance vessels of the lung [13]. During the process of remodelling, reconstruction of the intima with endothelial cell excrescences, proliferation of VSMCs and a resulting obliteration of the vessels were described $[13,14]$. Meanwhile, there is increasing evidence that endothelial cells do not proliferate in hypoxia-induced pulmonary hypertension [15], but the adventitia is also involved in the development of pulmonary hypertension [8]. Growth factors such as platelet-derived growth factor (PDGF) and its receptor (PDGFR) were found to be essential for the development of pulmonary hypertension, mediating proliferation and migration of VSMCs [16]. However, the proliferating cell population of vascular media has not yet been characterised in detail. In particular, there are no data indicating whether proliferating cells of the vascular media represent nestin-expressing progenitor cells.

The present study investigates the correlation of nestin expression with cell proliferation and vascular remodelling during development of pulmonary hypertension.

\section{Materials and methods}

Animals and tissues

The generation of nestin-GFP (green fluorescent protein) transgenic mice, expressing GFP under the control of the nestin gene promoter and a transcriptional enhancer that resides in the second intron of the gene, has been described previously [17].

Hypoxic pulmonary vascular remodelling in mice was induced by exposing C57BL/6 mice (Charles River Laboratories, Sulzfeld, Germany; at least five mice for each time point) to chronic hypoxia (normobaric; $10 \% \mathrm{O}_{2}$ ) in a ventilated chamber as described previously [18].

To induce pulmonary hypertension in rats, adult male Sprague-Dawley rats (Charles River) were subcutaneously injected with $60 \mathrm{mg} \cdot \mathrm{kg}^{-1}$ monocrotaline (MCT; Sigma, Munich, Germany) [19]. Alternatively, rats were injected subcutaneously with the vascular endothelial growth factor receptor 2 inhibitor SU5416 $\left(20 \mathrm{mg} \cdot \mathrm{kg}^{-1}\right)$ followed by exposure to chronic hypoxia (normobaric; $10 \% \mathrm{O}_{2}$ ) for 5 weeks.

Human explanted lung tissues were obtained during lung transplantation. Samples of donor lungs were taken from lungs that had not been transplanted.

For Western blot analyses, lung samples were frozen directly. For paraffin embedding, samples were fixed in Bouin fixative. For cryosections, lungs were either frozen directly or fixed with $4 \%$ paraformaldehyde at room temperature and impregnated with $30 \%$ sucrose-PB.

All experiments were approved by the local authorities (Regierungspräsidium Giessen; 17a-10c 20/15 (1)-Gi20/10-3/95 and 25.3-19c 20/15(1)-Gi20/10-20/99). The study protocol for tissue donation was approved by the Ethics Committee of the Medical Faculty (Justus-Liebig University Giessen, Germany) according to national law and with "Good Clinical Practice/International Conference on Harmonisation" guidelines. Written consent was obtained from each individual patient or the patient's next of kin (AZ 31/93).

\section{Immunostaining}

Immunohistochemistry was performed on frozen or paraffin-embedded tissue from mice, rats or humans and on human pulmonary artery smooth muscle cells (HPASMCs) in chambered slides. After microwave unmasking (for anti-Ki-67), sections were incubated with the following antibodies: monoclonal mouse anti-nestin (clone R401; Chemicon, Schwalbach, Germany; 1:100, for rat samples), mouse anti-nestin (BD Transduction, Heidelberg, Germany; 1:50, for mouse samples), mouse anti-nestin (Santa Cruz, Heidelberg, Germany; 1:50, for human samples), rabbit anti-calponin-1 (Epitomics, Hamburg, Germany; 1:1000), mouse anti-CD31 (BD Pharmingen, Heidelberg, Germany; 1:500), rat anti-CD31 (Dianova, Hamburg, 
Germany; 1:100), rabbit anti-von Willebrand factor (vWF) (Millipore, Billerica, MA, USA; 1:100), mouse anti- $\alpha$-smooth muscle actin (SMA) (Serotec, Oxford, UK; 1:500), mouse anti-proliferating cell nuclear antigen (PCNA) (Chemicon; 1:25) and polyclonal rabbit anti-Ki-67 (Novocastra, Wetzlar, Germany; 1:1000). For paraffin sections, an EnVision double-staining kit (DAKO, Hamburg, Germany) was used for primary antibody detection according to the manufacturer's instructions. For frozen sections and cultured cells, primary antibodies were detected by incubating the slides with secondary antibodies conjugated with Cy3 (Jackson ImmunoResearch, West Grove, PA, USA; 1:500), Alexa Fluor 488 (Molecular Probes, Eugene, OR, USA; 1:1000) or Alexa Fluor 594 (Molecular Probes; 1:1000). Cell nuclei of frozen sections were additionally stained with 4',6-diamidino-2-phenyl-indole (DAPI) (Sigma).

\section{CLARITY}

The CLARITY procedure is described in the online supplementary material.

\section{Small interfering RNA transfection and assessment}

HPASMCs were transiently transfected with nestin small interfering RNA (siRNA) (sc-36032; Santa Cruz) using Lipofectamine RNAiMAX transfection reagent (Invitrogen, Karlsruhe, Germany). Details to the siRNA and cell counting procedures are given in the online supplementary material.

\section{Protein preparation and immunoblotting}

Preparation of membrane and cytosolic proteins from lung tissue and HPASMCs, separation by SDS-PAGE under reducing conditions, and transfer of proteins to nitrocellulose membranes were performed as described previously [4]. After staining the membranes with Ponceau S (Sigma) and blocking the nonspecific binding sites, blots were exposed to primary antibodies: monoclonal mouse anti-nestin (Chemicon; 1:1000), mouse anti-nestin (BD Transduction; 1:1000), mouse anti-nestin (Santa Cruz; 1:200), mouse anti-vinculin (Sigma; 1:30 000), mouse anti- $\beta$-actin (Sigma; 1:20000), mouse anti-SMA (Sigma; 1:5000), polyclonal rabbit anti-PDGFR- $\beta$ (Upstate, Schwalbach, Germany; 1:500), rabbit anti-phospho-PDGFR- $\beta$ (p-PDGFR- $\beta$ ) (Santa Cruz; 1:250), rabbit anti-poly (ADP-ribose) polymerase 1 (PARP1) and rabbit anti-cleaved PARP (Cell Signaling Technology, Frankfurt, Germany; 1:1000). After washing, the membranes were probed with peroxidase-conjugated goat anti-rabbit IgG or goat anti-mouse IgG (Pierce, Rockford, IL, USA; 1:2000). Immunoreactive bands were visualised by enhanced chemiluminescence [4]. Densitometric quantification was performed using Image software (NIH, Bethesda, MD, USA).

\section{Statistical analysis}

Statistical analysis was performed using Prism 4 (GraphPad, San Diego, CA, USA). All data are presented as mean \pm SEM. Statistical significance was established at $\mathrm{p}<0.05$, using the unpaired $t$-test with Welch's correction.

\section{Results}

Nestin in lung vasculature

Nestin-GFP transgenic mice were investigated to determine the localisation of the intermediate filament nestin in lung. Distinct and exclusive nestin-GFP expression was observed in vessels (figure 1 and online supplementary video using a new CLARITY approach). Nestin-GFP ${ }^{+}$cells were found in arteries, capillaries and veins (figure $1 \mathrm{~b}$ and $\mathrm{c}$ ). In contrast, the airway system lacked nestin-GFP ${ }^{+}$cells (figure 1a and $\mathrm{c}$, and online supplementary video; see also figure $2 \mathrm{i}-\mathrm{k}$ ).

\section{Nestin is localised to VSMCs}

Here, we focused on nestin expression in lung arteries. To investigate which cell types express nestin, we used the endothelial marker CD31 and the smooth muscle cell-specific marker SMA. Nestin-GFP ${ }^{+}$cells could be clearly differentiated from $\mathrm{CD}_{3} 1^{+}$cells (figure $2 \mathrm{a}-\mathrm{h}$ ), whereas co-localisation of nestin-GFP and SMA was observed (figure $2 \mathrm{i}-\mathrm{q}$ ). Smooth muscle cells of the bronchioli also showed SMA staining, but no nestin-GFP signal (figure 2i-k). The GFP staining, observed in the cytoplasm and cell nuclei as described previously [17] (see figure 2l-o), was visible only in a subpopulation of $\mathrm{SMA}^{+}$cells (figure $2 \mathrm{p}-\mathrm{q}$ ).

Nestin expression and cell proliferation in animal models of pulmonary hypertension

We investigated potential changes in nestin expression in different models of pulmonary hypertension that are characterised by structural changes of the lung associated with high cell proliferation.

\section{Hypoxic mouse model}

Cell proliferation (indicated by Ki-67 and PCNA) and the time course of nestin expression were investigated in the hypoxic mouse model (figure 3). Nestin expression significantly increased in lungs of hypoxia-exposed animals between 3 days and 1 week, but returned to normoxic levels after 3 weeks (figure $3 \mathrm{a}$ and $\mathrm{b}$ ). In this model, vascular remodelling is known to be histologically visible and pulmonary hypertension is clinically 

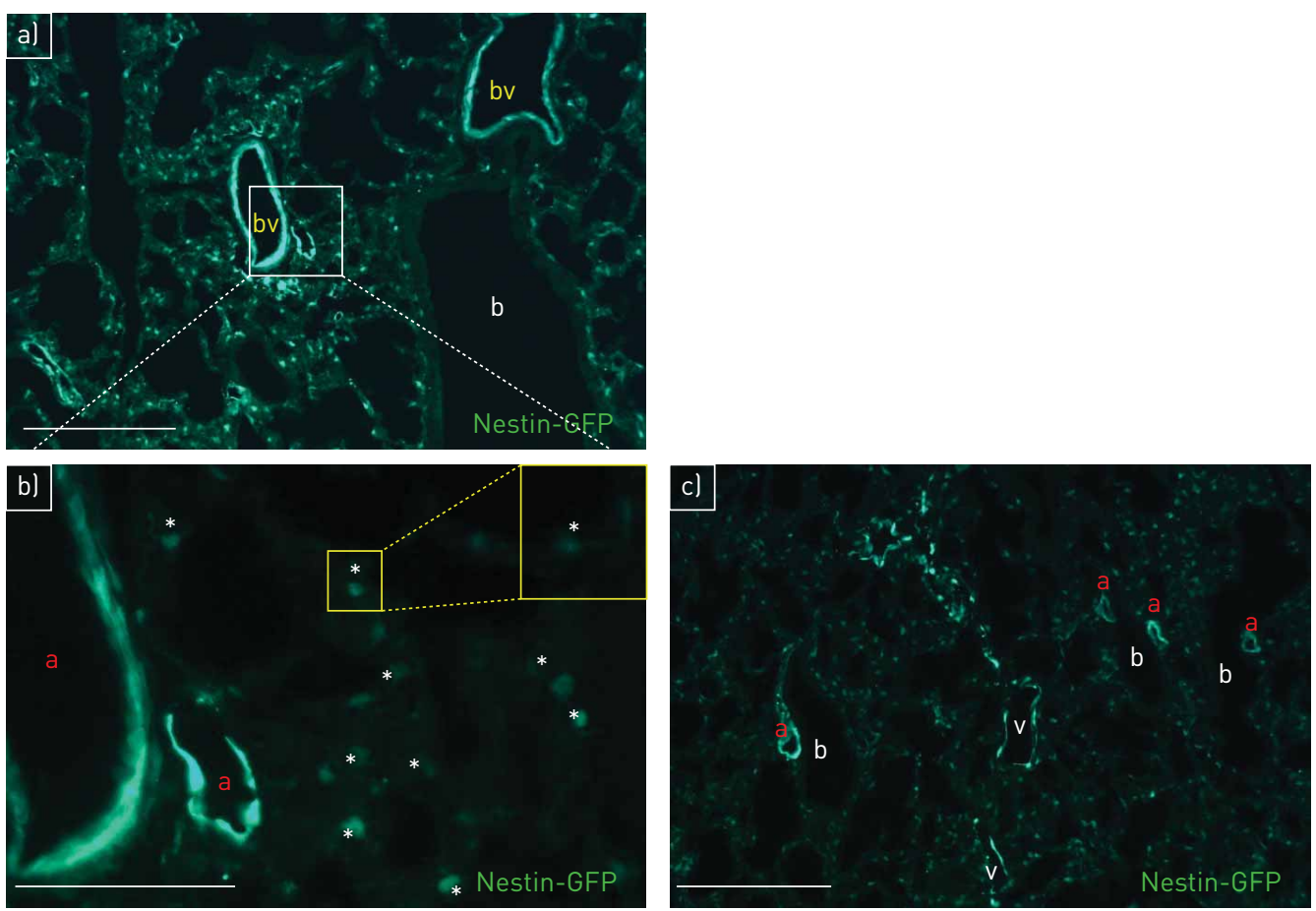

FIGURE 1 Localisation of nestin-GFP (green fluorescent protein) in lung vasculature. a) Nestin-GFP ${ }^{+}$cells are detectable in pulmonary blood vessels (bv); bronchioli (b) are nestin-GFP ${ }^{-}$; day 1. b) (detail of panel a at higher magnification) Nestin-GFP cells in arteries (a) and capillaries (asterisks mark the lumen); day 1. c) Nestin-GFP cells in arteries (a) and veins (v); bronchioli (b) are nestin-GFP'; day 1. Scale bars: a, c) $100 \mu \mathrm{m}$; b) $50 \mu \mathrm{m}$.

evident at later time points different to the days of nestin peaks. Expression of SMA, however, barely differed among single time points (online supplementary figure S1).

An increased number of $\mathrm{PCNA}^{+}$and $\mathrm{Ki}-67^{+}$VSMCs was detectable after 3 days to 1 week of hypoxic treatment (figure $3 \mathrm{c}$ and $\mathrm{n}$ ). After 3 weeks, $\mathrm{PCNA}^{+}$and $\mathrm{Ki}-67^{+}$VSMCs could hardly be observed (figure $3 \mathrm{f}$ and $\mathrm{j}$ ), corresponding to low nestin expression.

Double staining of hypoxic samples with SMA and PCNA indicated that $\mathrm{SMA}^{+}$cells are the predominant cell population showing proliferation in hypoxia-induced vascular remodelling (figure $3 \mathrm{k}-1$ ). Nestin was found in proliferating VSMCs as demonstrated by co-localisation of nestin and Ki-67 (figure 3m-n).

In addition, Western blot analyses of the time course of activated (phosphorylated) PDGFR- $\beta$, which is known to contribute to the development of pulmonary hypertension, also showed transiently elevated expression between 4 and 7 days of hypoxia (figure $4 \mathrm{~b}-\mathrm{d}$ ), whereas expression of total PDGFR- $\beta$ slightly increased alongside progressing pulmonary hypertension (figure 4a).

In agreement with the hypoxic model, rapid remodelling of lung vasculature during post-natal development was also characterised by high nestin expression and a high number of proliferating $\left(\mathrm{PCNA}^{+}\right.$) VSMCs (online supplementary figure S2), with a peak between post-natal days 3 and 10 and a decline towards adulthood. Interestingly, the smooth muscle cell differentiation marker calponin (nearly exclusively expressed by bronchial smooth muscle cells; data not shown) showed an inverse correlation to nestin (online supplementary figure S2), whereas expression of the general smooth muscle cell marker SMA (expressed by all smooth muscle cells; data not shown) remained unchanged. The same was found in VSMCs of the hypoxic pulmonary hypertension model (data not shown).

Nestin expression in rat models of pulmonary hypertension

To investigate whether nestin ${ }^{+} / \mathrm{SMA}^{+}$cells are also involved in vascular remodelling in rats, nestin expression was evaluated in MCT-treated (figure 5) and SU5416/hypoxia-treated (figure 6) rat lungs.

\section{MCT rat model}

Immunohistochemical analyses revealed nestin ${ }^{+}$cells 3 weeks after MCT treatment (figure 5a). As shown by double staining, co-localisation of nestin and SMA was observed in VSMCs (figure 5b). Staining of 

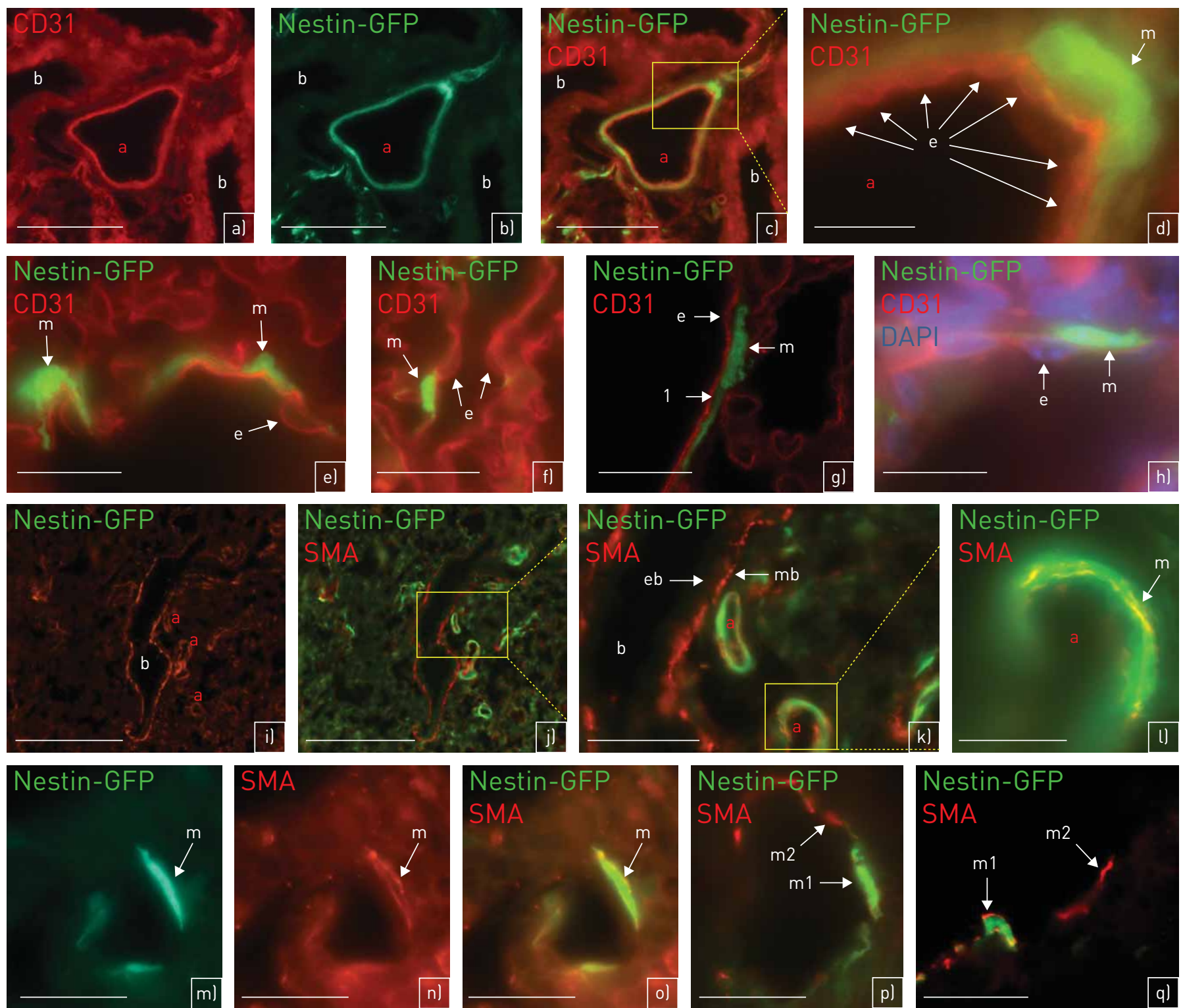

FIGURE 2 Nestin-GFP (green fluorescent protein) is co-localised with the smooth muscle cell marker smooth muscle actin (SMA), but not with the endothelial cell marker CD31. a-h) Nestin-GFP (green) and CD31 (red) (a-d, h: day 1; e-g: adult). a-d) Artery (a): nestin-GFP is not co-localised with CD31. Bronchioli (b) are nestin-GFP- (a: CD31; b: nestin-GFP; c: merge). d) (detail of panel $c$ at higher magnification) The nestin-GFP ${ }^{+}$vascular smooth muscle cell (VSMC) (m) is outside of CD31+ endothelial cells (e). e, f) Single nestin-GFP ${ }^{+}$VSMCs (m). They are not co-localised with CD $31^{+}$endothelial cells (e). g) (confocal microscopy) Clear separation (labelled by "1") between the CD31 $1^{+}$layer of endothelial cells (e) and the nestin-GFP ${ }^{+}$layer of VSMCs (m). h) Additional staining with 4',6-diamidino-2-phenyl-indole (DAPI); DAPI clearly reveals the nuclei from CD31 ${ }^{+}$endothelial cells (e). m: nestin-GFP+ VSMC. i-q) Nestin-GFP (green) and SMA (red) (i-o: day $1 ; p, q:$ adult). i, j) Nestin-GFP $/ S M A^{+}$ arteries (a) are adjacent to a nestin-GFP ${ }^{-} \mathrm{SMA}^{+}$bronchiolus (b) (i: SMA; j: SMA and nestin-GFP). k) (detail of panel $j$ at higher magnification) Nestin-GFP $/ \mathrm{SMA}^{+}$VSMCs of arteries (a); smooth muscle cells of bronchioli (mb) are $\mathrm{SMA}^{+} /$nestin-GFP ${ }^{-}$. The epithelium of bronchioli (eb) is $\mathrm{SMA}^{-}$. I) (detail of an artery of panel $k$ at higher magnification) Nestin-GFP+/SMA+ VSMCs (m) of an artery (a). m-o) (m: nestin-GFP; $n$ : SMA; 0 : merge) Nestin-GFP $/ \mathrm{SMA}^{+}$VSMC (m). SMA is present in the cytoplasm (n: red), Nestin-GFP is located to the cytoplasm (o: yellow) and the nucleus

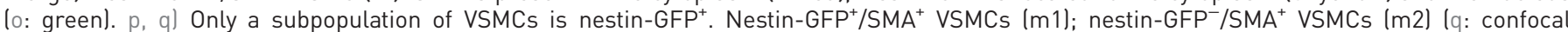
microscopyl. Scale bars: a-c) $75 \mu \mathrm{m}$; d, m, n, ol $15 \mu \mathrm{m}$; e-g, q) $20 \mu \mathrm{m}$; h, l, p) $25 \mu \mathrm{m}$; i, j) $100 \mu \mathrm{m}$; k) $50 \mu \mathrm{m}$.

serial sections with nestin and the endothelial cell markers vWF (figure $5 \mathrm{c}$ and d) and CD31 (figure 5e and f), however, could exclude nestin expression from endothelial cells.

In MCT-treated samples, nestin upregulation was only observed in the pulmonary artery. In the aorta, however, no difference in nestin expression was detectable between MCT-treated and control/untreated animals (online supplementary figure S3). We therefore suggest that changes in nestin expression after MCT treatment are specific for the pulmonary circulation, reflecting the peculiarities of MCT metabolism [20]. 
a)

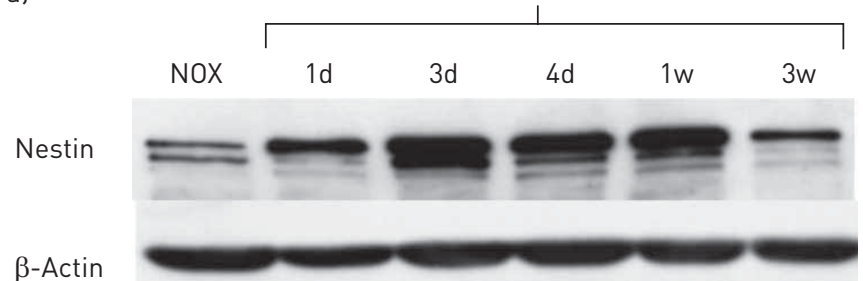

NOX
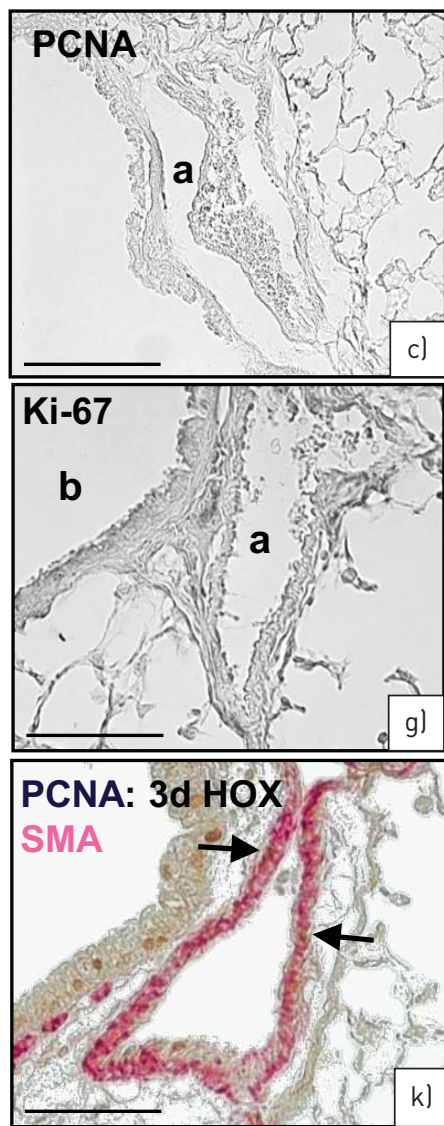

$3 d$

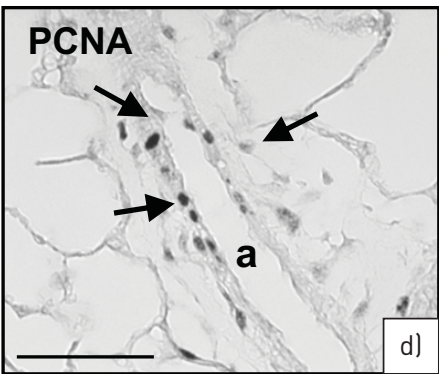

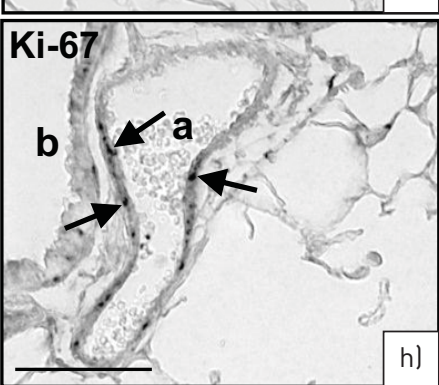

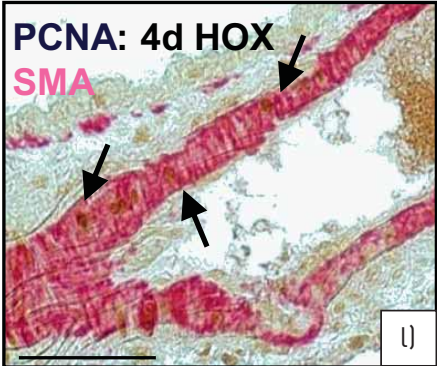

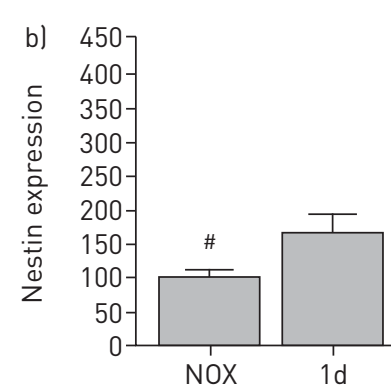

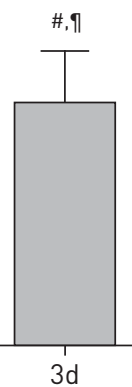

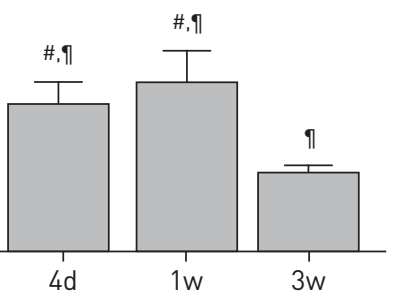

$1 \mathrm{w}$

$3 w$
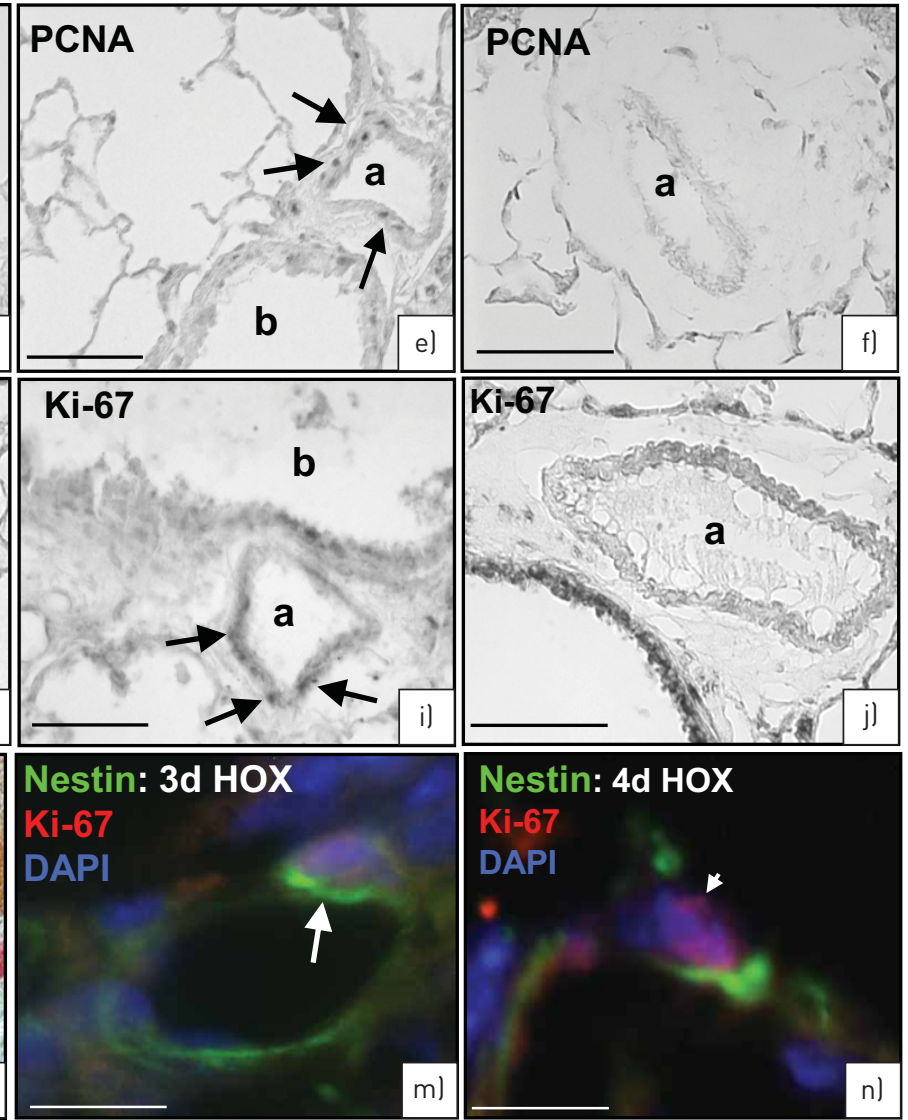

FIGURE 3 Hypoxic mouse model. Nestin expression and cell proliferation in wild-type mice after hypoxia (HOX). a) Immunoblots demonstrate increased nestin expression after hypoxia; the maximum of nestin expression is between 3 days and 1 week after hypoxia followed by decrease in expression after 3 weeks (120 $\mu \mathrm{g}$ cytosolic protein). b) Densitometric quantification of nestin. Bars show mean \pm SEM scores from three assessments with $\beta$-actin as loading control. ", ${ }^{p}<0.01$ (": normoxia (NOX) was compared with 3 days, 4 days and 1 week; " : 3 weeks was compared with 3 days, 4 days and 1 week). c-f) Proliferating cell nuclear antigen (PCNA) immunostaining. c) Normoxia: no PCNA-marked cells. d, e) 3 days hypoxia (d) and 1 week hypoxia (e): numerous PCNA-marked vascular smooth muscle cell (VSMCs). f) 3 weeks hypoxia: no PCNA-marked cells. g-j) Ki-67 immunostaining. g) Normoxia: no Ki-67-marked cells. h, i) 3 days hypoxia (h) and 1 week hypoxia (i): numerous Ki-67-marked VSMCs. j) 3 weeks hypoxia: no Ki-67-marked cells. k, l) 3 days ( $\mathrm{k}$ ) and 4 days (U) hypoxia: PCNA (brown) is localised to smooth muscle actin (SMA) ${ }^{+}$VSMCs (red). $\left.\mathrm{m}, \mathrm{n}\right) 3$ days (m) and 4 days (n) hypoxia: the proliferation marker Ki-67 (red, arrowhead) is co-localised with nestin (green, arrow) in the same cell. Nuclei are stained with 4',6-diamidino-2-phenyl-indole (DAPI) (blue). 1d: 1 day; 3d: 3 days; 4d: 4 days; $1 w: 1$ week; 3w: 3 weeks. Scale bars: a, g, k-n) $75 \mu m$; d-f, h-j) $75 \mu m$.

SU5416/hypoxia rat model

Similarly, in lungs from the SU5416/hypoxia model, nestin expression in VSMCs of the arterial media could be confirmed by double staining with SMA (figure $6 \mathrm{a}$ and $\mathrm{b}$ ) as well as by serial sections stained for nestin with CD31 (figure $6 \mathrm{c}$ and $\mathrm{d}$ ) and SMA (figure 6e and f).

In certain arteries $(\sim 60-80 \mu \mathrm{m}$ diameter $)$ of rats from this model, which is also characterised by distinct neointima formation [21], a thickened intima of different phenotype could be observed. In all such arteries, nestin was expressed in a subpopulation of $\mathrm{SMA}^{+}$cells of the media and, most interestingly, also in $\mathrm{SMA}^{+}$ cells of the intima (figure $6 \mathrm{~g}$ versus $\mathrm{h}$, $\mathrm{i}$ versus $\mathrm{j}, \mathrm{k}$ versus 1 and $\mathrm{m}$ versus $\mathrm{n}$ ). When different arteries with 
a)
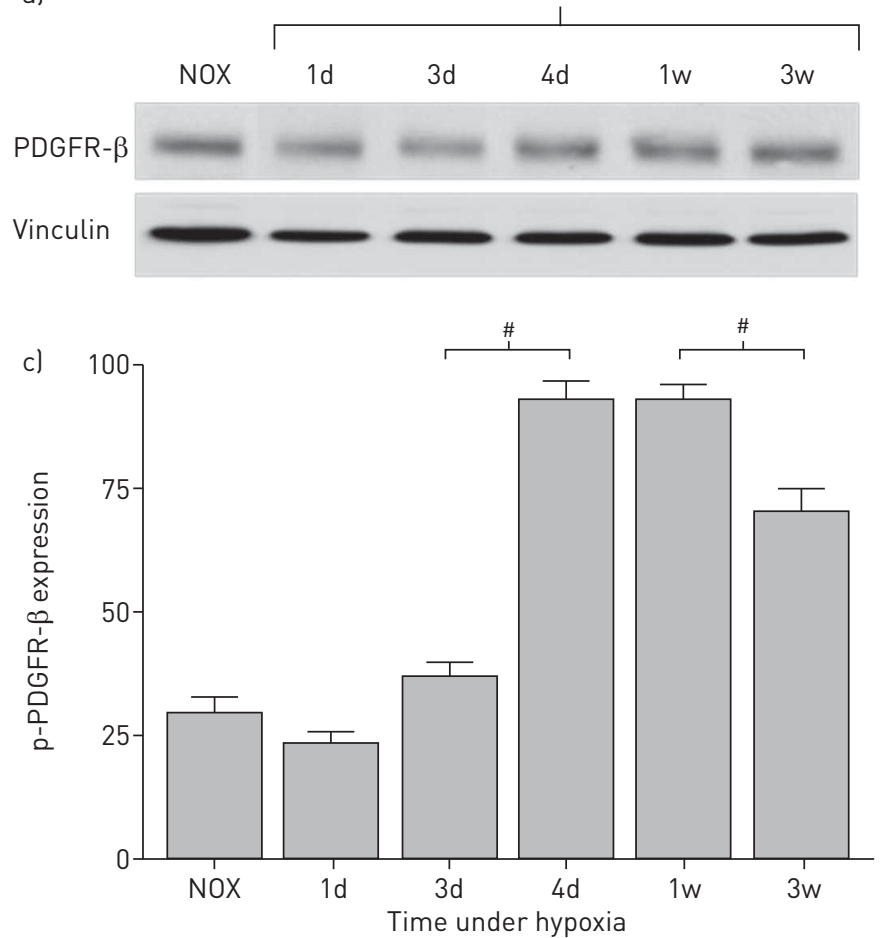

b)

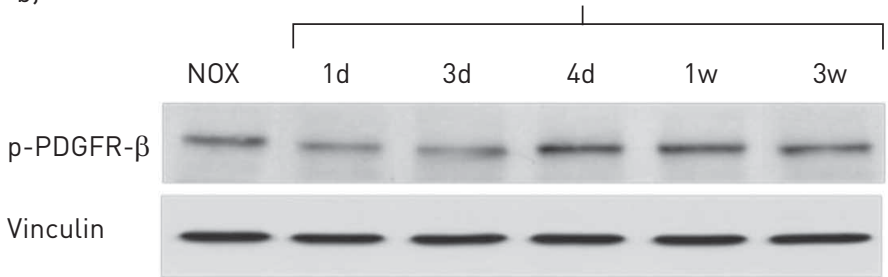

d)

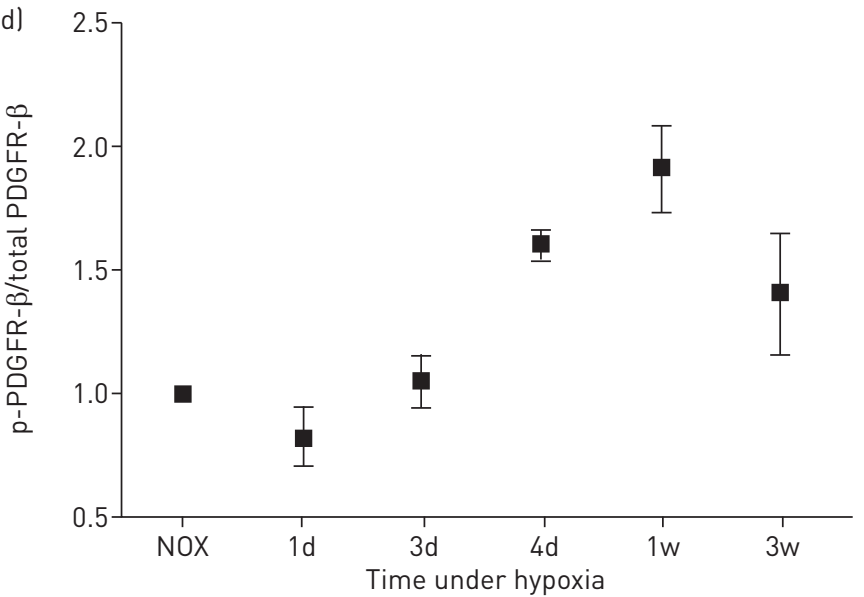

FIGURE 4 Platelet-derived growth factor receptor $\beta$ (PDGFR- $\beta$ ) expression in hypoxic mouse lung samples. a) PDGFR- $\beta$ Western blot shows only a slight increase in PDGFR- $\beta$ expression during hypoxic exposure towards 3 weeks ( $30 \mu$ membrane protein). b) Phospho (p)-PDGFR- $\beta$ Western blot shows a peak of activated (phosphorylated) PDGFR- $\beta$ after 4 days hypoxia (30 $\mu$ g membrane protein). c) Densitometric quantification of p-PDGFR- $\beta$ expression. Bars show mean \pm SEM scores from three assessments. ${ }^{\#}: p<0.01$ indicates significant differences in $p-P D G F R-\beta$ expression between 3 and 4 days as well as between 1 and 3 weeks. Vinculin was used as loading control. d) PDGFR- $\beta$ activity expressed as p-PDGFR- $\beta /$ PDGFR- $\beta$ ratio. NOX: normoxia; 1d: 1 day; 3 d: 3 days; 4 d: 4 days; 1 w: 1 week; 3 w: 3 weeks.

thickened intima, correlating to different grades of neointimal development [21], were compared, a decrease of nestin ${ }^{+} / \mathrm{SMA}^{+}$cells in the inner part of the media together with an increase of nestin ${ }^{+} / \mathrm{SMA}^{+}$cells in the (neo)-intima became evident during development (figure $6 \mathrm{~g}-\mathrm{n}$ ). Endothelial cells of the vessels with complex neointima formation also did not show nestin immunostaining (figure $6 \mathrm{k}$ and $\mathrm{m}$, inset).

Nestin expression and function in human samples

Next, we studied the role of nestin in humans.

\section{Human samples from patients suffering from pulmonary hypertension}

In healthy controls (figure $7 \mathrm{a}$ ), nestin ${ }^{+}$cells were barely detectable. In human pulmonary hypertension, however, an increased number of nestin ${ }^{+}$cells was found in the media of regular lung arteries (figure $7 \mathrm{~b}$ ) as well as in specific vascular lesions which have been described to be also characteristic for human pulmonary hypertension [22] (figure $7 \mathrm{~d}, \mathrm{e}, \mathrm{g}$ and i). In agreement with the animal models, nestin expression could be ascribed to smooth muscle cells as indicated by staining of serial sections for nestin and SMA (figure $7 b$ and $c, g$ and $h$, and $i$ and $j$ ) or for nestin and vWF (figure $7 e$ and $f$ ). In general, the number of nestin ${ }^{+}$VSMCs was lower in those vessels in which pathological changes were already pronounced. For comparison, samples with idiopathic pulmonary fibrosis (IPF) were investigated and interestingly also showed nestin ${ }^{+}$VSMCs in the arterial media (figure $7 \mathrm{k}$ and 1 ).

\section{Human isolated pulmonary VSMCs}

To address nestin function, we employed a gene ablation approach using nestin siRNA in isolated HPASMCs and revealed a reduced cell number associated with nestin knock-down (online supplementary figure S4). In this context, there was no evidence for enhanced apoptosis (online supplementary figure S4). Nestin siRNA-treated HPASMCs did not show expression of the apoptosis marker cleaved PARP (produced by caspase cleavage), which is different to the full-length PARP enzyme. Staurosporine-treated HeLa cells served as a positive control in these Western blot assays. 

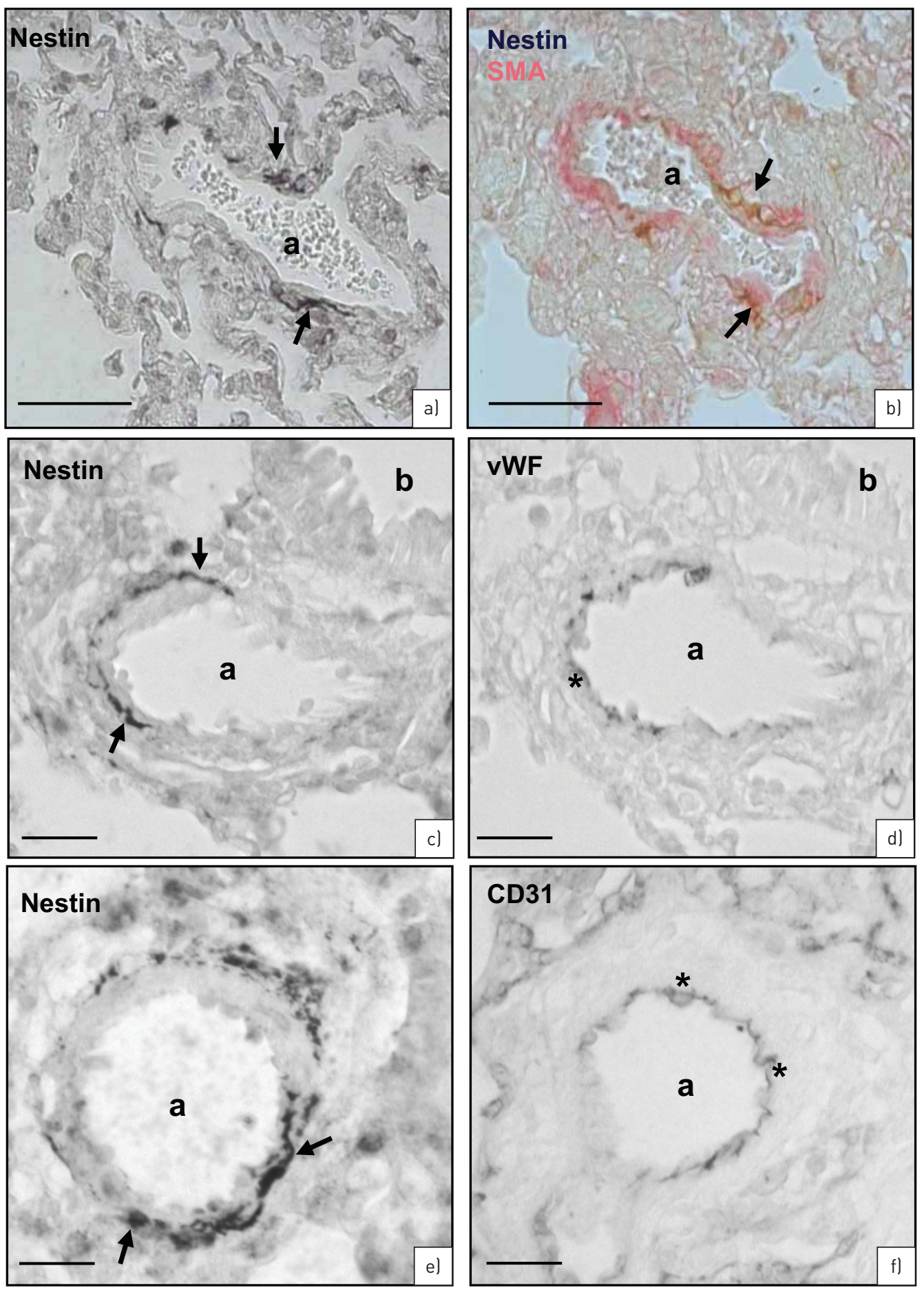

FIGURE 5 Rat monocrotaline (MCT) model. Nestin immunostaining in rat lungs 3 weeks after MCT treatment. a) Single nestin ${ }^{+}$vascular smooth muscle cells (VSMCs) (arrows) in an artery (a). b) Nestin (brown, arrows) is localised to a subpopulation of smooth muscle actin (SMA) ${ }^{+}$cells (red). c, d) Serial sections of nestin (c: arrows) and von Willebrand factor (vWF) (d: asterisks) immunostaining. Bronchioli (b). e, f) Serial sections of nestin (e: arrows) and CD31 (f: asterisks) immunostaining. Scale bars: a, b) $50 \mu \mathrm{m}$; c-f) $25 \mu \mathrm{m}$.

In agreement, untreated HPASMCs showed double staining for both nestin and the proliferation marker Ki-67 (online supplementary figure S4). Only a few cells of a more differentiated phenotype failed to express nestin and instead were positive for markers of differentiated smooth muscle cells, such as calponin $[23,24]$ (online supplementary figure S4). 

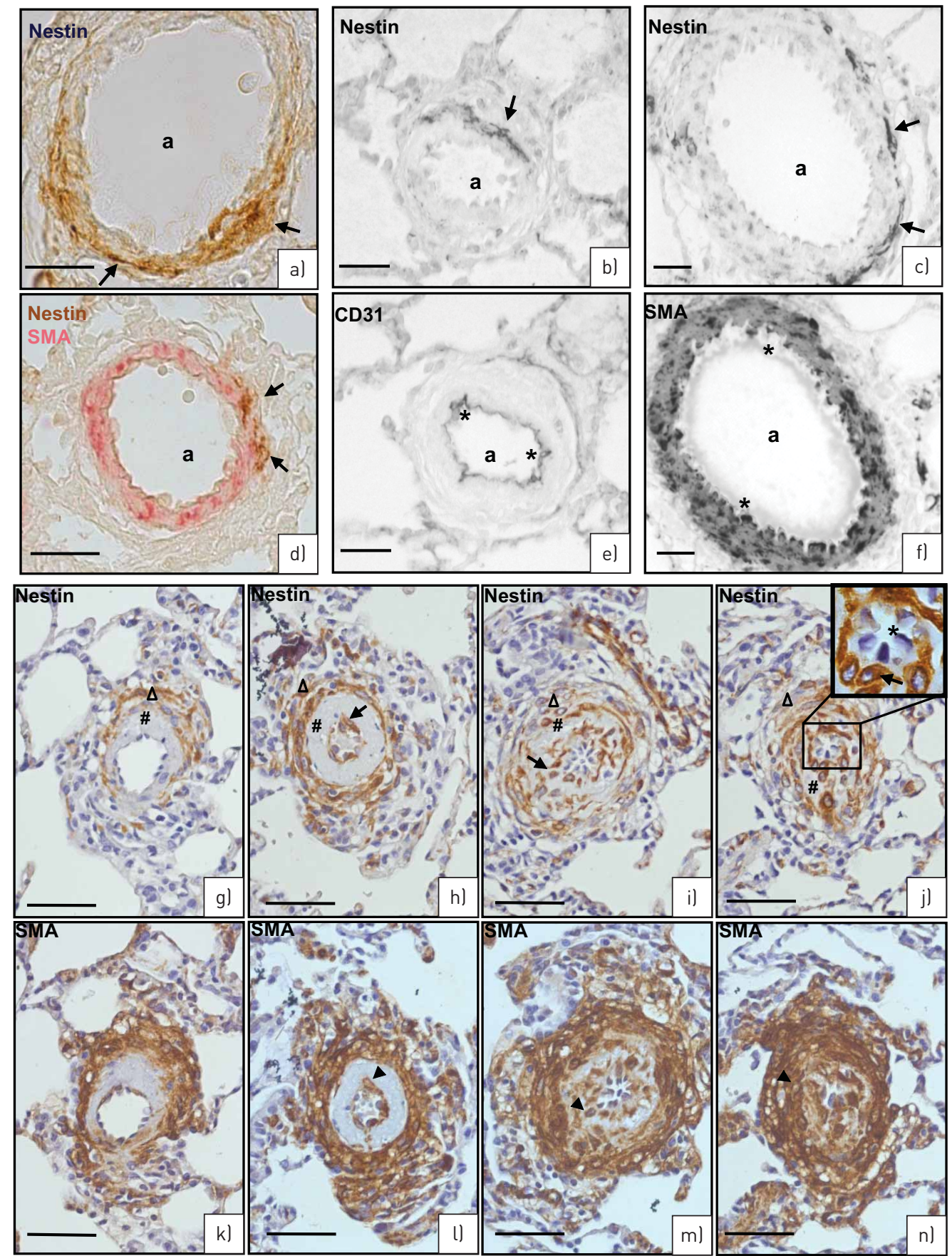

FIGURE 6 SU5416/hypoxia rat model of pulmonary hypertension. a) Nestin staining (brown, arrows) in the wall of an artery (a). b) Double staining, nestin (brown, arrows) in a subpopulation of smooth muscle actin (SMA) ${ }^{+}$ vascular smooth muscle cells (VSMCs) (red). c, d) Serial sections of nestin (c: arrows) and CD31 (d: asterisks) immunostaining. e, f) Serial sections of nestin (e: arrows) and SMA (f: asterisks mark SMA- endothelial cells) immunostaining. g-n) Different grades of neointima development. Serial sections stained for nestin ( $g, i, k, m$ : arrows) and SMA (h, j, L, n: arrowheads) in the (neo)intima (\#) and media $(\Delta)$ of arteries $(60-80 \mu \mathrm{m})$ of the single stages ( $g$ and $h, i$ and $j, k$ and $l$, and $m$ and $n)$. Note the decrease of nestin ${ }^{+} / \mathrm{SMA}^{+}$cells in the media in contrast to their increase in the (neo)intima from $\mathrm{g} / \mathrm{h}$ to $\mathrm{m} / \mathrm{n}$. Endothelial cells in the inset of panel $\mathrm{m}$ are marked with asterisks. Scale bars: a, b, g-n) $50 \mu \mathrm{m} ; \mathrm{c}$, d) $25 \mu \mathrm{m}$; e, f) $10 \mu \mathrm{m}$.

\section{Discussion}

We were able to identify the intermediate filament nestin, known to characterise progenitor cells in the nervous system, in a subpopulation of VSMCs involved in vascular remodelling during the development of pulmonary hypertension. Summarising the data of different models and human samples of pulmonary hypertension, we suggest that increased nestin expression is the first evidence of the changes in the 

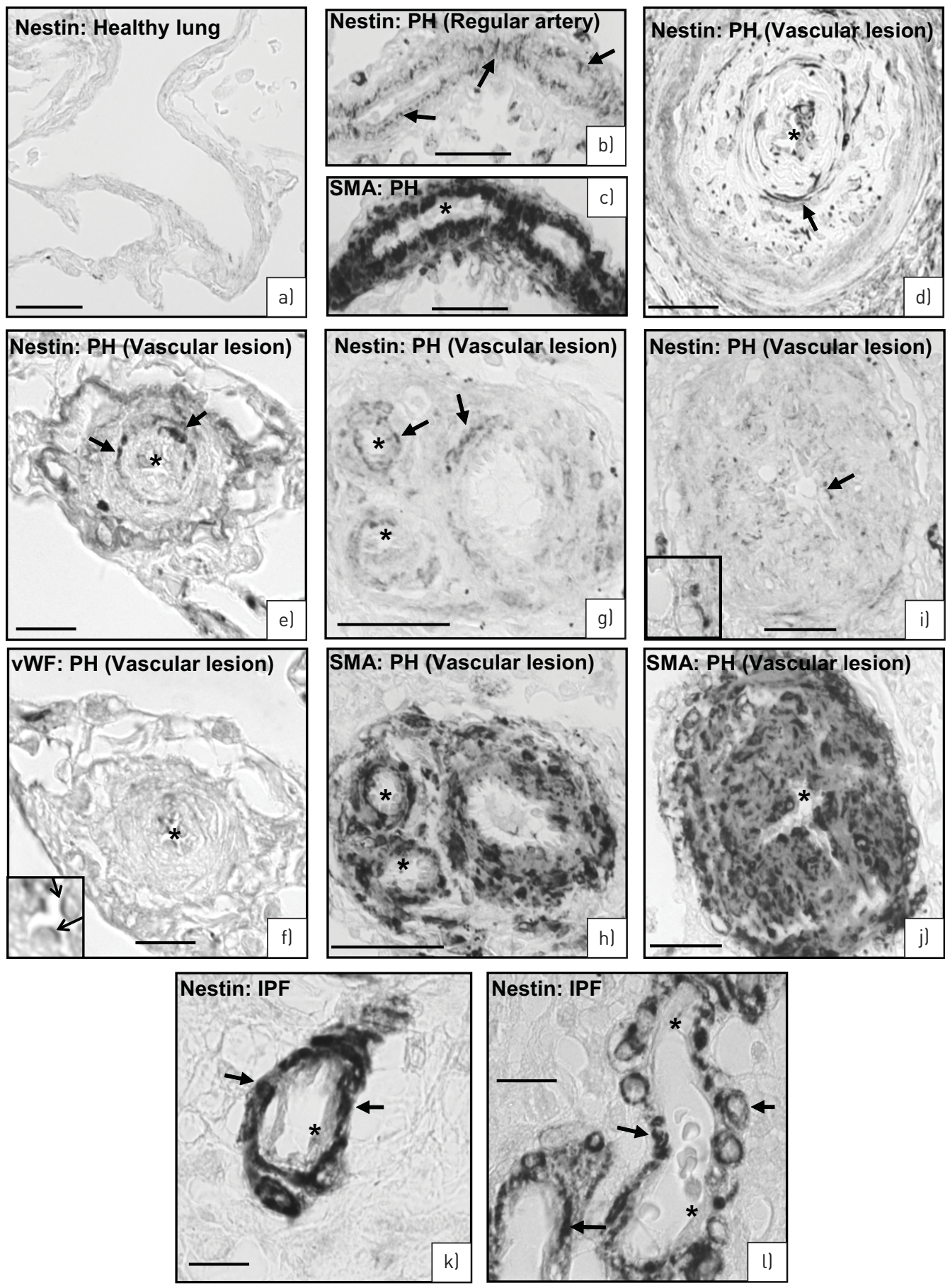

FIGURE 7 Human lungs. a) Healthy lung. No nestin-expressing cells. b-j) Pulmonary hypertension (PH) lungs. b, c) Serial sections of a regular artery stained for nestin (b: arrows) and smooth muscle actin (c: asterisks mark SMA ${ }^{-}$endothelial cells). d) Artery with complex lesion stained for nestin (arrows). e-j) Serial sections of three different arteries with complex lesions stained for nestin (e: arrows) and von Willebrand factor (vWF) ( $f$, inset: arrows) as well as nestin (g, i: arrows) and SMA (h, j: asterisks mark SMA negative-endothelial cells). $k-l$ ) Idiopathic pulmonary fibrosis (IPF) lung. Nestin immunoreactivity in smooth muscle cells (arrows) of the arterial media. Asterisks mark lack of nestin staining in endothelial cells. Scale bars: a-d, g-j) $50 \mu \mathrm{m} ; \mathrm{e}, \mathrm{f}, \mathrm{k}, \mathrm{l}) 10 \mu \mathrm{m}$.

vasculature, immediately followed by proliferation of nestin ${ }^{+} / \mathrm{SMA}^{+}$cells, activation of the PDGFR- $\beta$ [16, 19] pathway and decrease of calponin, whereas SMA expression remained nearly unchanged (figure 8).

Using different methods, including novel CLARITY [25] approaches, nestin expression was exclusively found in VSMCs and was never detected in (para)bronchial smooth muscle cells or other proliferating cell types of the lung, such as bronchial epithelial cells. We therefore suggest that nestin is neither a simple 


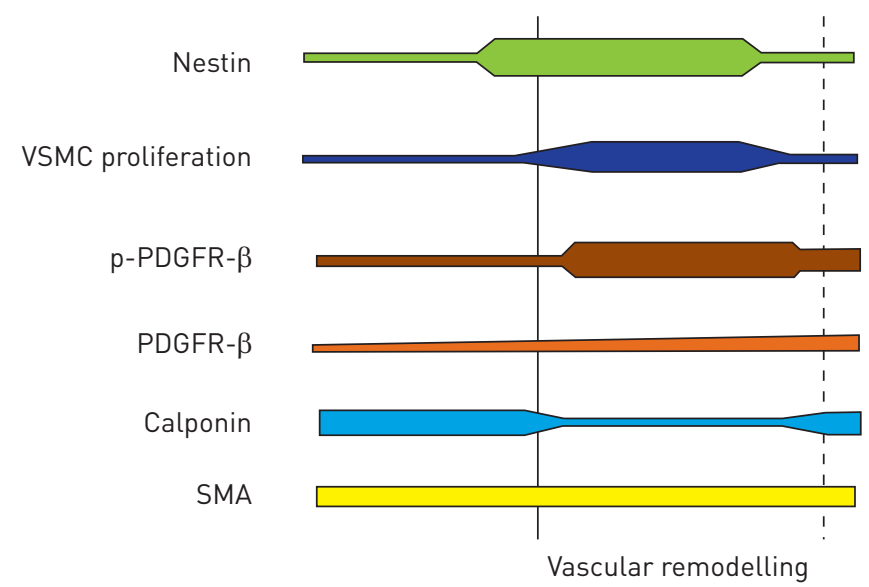

FIGURE 8 Schematic demonstration of temporal changes in vascular remodelling during the development of pulmonary hypertension. Nestin appears as the first indicator of structural changes together with proliferation of vascular smooth muscle cell (VSMC) progenitor cells followed by activation of platelet-derived growth factor receptor $\beta$ (PDGFR- $\beta$ ) (indicated by phospho (p)-PDGFR- $\beta$ ) and the decrease of calponin. Smooth muscle actin (SMA) expression remained unchanged. The dotted line indicates clinically established pulmonary hypertension.

proliferation marker for lung cells nor a simple marker of lung smooth muscle cells. Instead, nestin marks exclusively VSMCs during proliferation, which is a rare event under physiological conditions [26], but is provoked during vascular remodelling $[27,28]$. In nearly all previous papers dealing with nestin-expressing cells, nestin marks progenitor or stem cells $[1,2]$. Thus, it can be assumed that nestin ${ }^{+}$cells in the lung also label a special type of cell. Currently, we cannot decide whether nestin ${ }^{+}$cells represent true stem/ progenitor cells of the vascular media or mark a synthetic phenotype of VSMCs.

In the latter case, our results would provide convincing evidence for a specific and functionally relevant marker protein of synthetic VSMCs, allowing them to be discriminated from all other smooth muscle cells. VSMCs are considered to de-differentiate and change their phenotype from contractile to synthetic under certain conditions [27], including vascular remodelling [26, 27]. In this study, expression of calponin marking differentiated smooth muscle cells $[23,24]$, in contrast to the more general contractile marker SMA, negatively correlated with nestin expression and proliferation of VSMCs. Similarly, nestin expression in isolated pulmonary VSMCs (HPASMCs) was found in proliferating $\mathrm{Ki}-67^{+}$cells, but not in calponin ${ }^{+}$cells.

Assuming that nestin ${ }^{+}$cells indeed represent stem/progenitor cells also in lung, our data would argue for the provocative theory that only a certain population of vascular smooth muscle (stem) cells is capable of proliferation in the vascular media [27]. Our previous results in testis [4] also showed nestin ${ }^{+}$progenitor cells residing in the vessel wall.

Interestingly, after 3 weeks under hypoxia, when complete histological characteristics and distinct clinical symptoms are established, expression of nestin and proliferation return to low levels again. PADDENBERG et al. [29] proposed that cell proliferation in the first week is followed by hypertrophy of VSMCs. Our study now allows us to identify the subpopulation of proliferating $\mathrm{SMA}^{+}$cells by expression of nestin, which can be regarded as an initial indicator for structural vascular changes.

In all pulmonary hypertension models, we were able to demonstrate nestin ${ }^{+} / \mathrm{SMA}^{+}$cells in arterial media. The SU5416/hypoxia model can be distinguished by characteristic vascular lesions, including formation of neointima [21]. Neointima is formed as a result of proliferation and migration of vascular cells towards the lumen, and smooth muscle cells were suggested to be the main contributors to this process [14, 26, 30, 31]. In our study, we found that neointima $\mathrm{SMA}^{+}$cells of lung arteries also express nestin comparable to balloon-injured carotid arteries [6]. The types of neointima lesions we detected in the SU5416/hypoxia model correspond to the different grades of neointimal lesions occurring over time, as described previously [21]. Thus, the nestin ${ }^{+} / \mathrm{SMA}^{+}$cells might be the particular cells migrating into and proliferating in the intima.

Human lungs of end-stage pulmonary hypertension are characterised by complex vascular lesions [22] and also comprise vessels in which morphological changes are not yet visible. Nestin is also expressed by VSMCs in both types of vessels. In regular vessels, nestin expression can be found in the vast majority of VSMCs, whereas vessels with pathological changes are characterised by only a few scattered nestin ${ }^{+}$VSMCs. This characteristic relationship suggests the involvement of nestin ${ }^{+} / \mathrm{SMA}^{+}$cells also in the formation of vascular lesions of human pulmonary hypertension, where accumulation of "SM-like cells" was described [9]. 
Nestin-ablated HPASMCs did not show an increase in cell number compared with controls without evidence of apoptosis. These findings support a functional association of nestin expression with regulation of cell number that has also been evoked in previous studies where nestin knock-down by siRNA was shown to effectively suppress the growth of C6 astrocytoma cells [32]. In addition, microRNA miR-125b was recently found to inhibit neural progenitor cell proliferation by targeting nestin [33]. The molecular role of nestin is still undefined, but phosphorylation and dephosphorylation of nestin may modulate cytoskeletal assembly and turnover [34], likely playing a significant role in increased cytoplasmic trafficking of stem/progenitor cells undergoing proliferation, migration and differentiation $[1,35,36]$. Regarding the function of nestin, however, it has to be considered that nestin knockout mice appear to be viable [37].

In the present study, as well as in our previous study in testis [4], we found nestin not only in VSMCs, but also in pericytes of capillaries, in agreement with more recent reports [12,38]. Pericytes, in addition to other functions [39], have been shown to represent stem/progenitor cells for cell types such as adipocytes, chondroblasts, osteoblasts, skeletal muscle fibres, Leydig cells and neuronal cells [4, 5, 39]. Leydig cell progenitors were found to be not only nestin ${ }^{+}$pericytes, but also nestin ${ }^{+}$VSMCs [4]. Whether nestin ${ }^{+}$ VSMCs in lung also represent progenitors for extravascular cell types remains speculative, but was recently discussed intensively for endothelial denudation injury of carotid arteries [27, 40]. Interestingly, tissue from patients with chronic thromboembolic pulmonary hypertension was described to contain progenitor cells which were able to give rise to adipocytes and underwent osteogenic differentiation [9].

TANG et al. [40] tested nestin expression in their proposed VSMC progenitors after several days in cell culture. The authors interpreted nestin expression as a developmental step towards cells of the neural lineage. Nestin expression in cells prior to or immediately after isolation was, however, not investigated. We propose that nestin expression does not indicate neural differentiation, but represents a specific characteristic of progenitor cells/VSMCs implicated in proliferation.

Endothelial cells were nestin ${ }^{-}$and did not show any proliferation in pulmonary vascular remodelling. This finding is consistent with previous data where endothelial cells did not show proliferation in mice and rats with hypoxia-induced pulmonary hypertension in vivo, and in human pulmonary artery endothelial cells also under hypoxia in vitro [15]. However, a series of studies had also suggested the relevance of endothelial progenitor cells [9].

Interestingly, in human tissue, we found high nestin expression beyond pulmonary hypertension also in arterial media of IPF lungs. Pulmonary fibrosis is associated with vascular changes as patients suffering from fibrosis may also develop severe pulmonary hypertension [41]. These nestin ${ }^{+}$cells may contribute to fibrotic processes as a source of myofibroblasts, in agreement with other studies [11].

Here, we describe nestin as a functionally relevant marker of undifferentiated cells promoting tissue regeneration and repair. In oncology, nestin has been described as a prognostic marker for survival, allowing the development of individualised treatment options $[42,43]$. In our hypoxic model, nestin expression appears earlier than the clinical and histological symptoms in the progression of pulmonary hypertension. Thus, certain vascular cells implicated in proliferation can be identified by nestin, and may be used as prognostic markers and new therapeutic targets for devastating diseases such as pulmonary hypertension.

\section{Acknowledgements}

We are grateful to Sabine Tasch, Ingrid Schneider-Hüther, Jörn Lübberstedt, Karin Quanz and Ingrid Breitenborn-Müller for technical support, and to Gabriela Krasteva-Christ for assistance at the beginning of our confocal microscopy studies.

\section{References}

1 Lendahl U, Zimmerman LB, McKay RD. CNS stem cells express a new class of intermediate filament protein. Cell 1990; 60: 585-595.

2 Wiese C, Rolletschek A, Kania G, et al. Nestin expression - a property of multi-lineage progenitor cells? Cell Mol Life Sci 2004; 61: 2510-2522.

3 Alliot F, Rutin J, Leenen PJ, et al. Pericytes and periendothelial cells of brain parenchyma vessels co-express aminopeptidase N, aminopeptidase A, and nestin. J Neurosci Res 1999; 58: 367-378.

4 Davidoff MS, Middendorff R, Enikolopov G, et al. Progenitor cells of the testosterone-producing Leydig cells revealed. J Cell Biol 2004; 167: 935-944.

5 Dore-Duffy P, Katychev A, Wang X, et al. CNS microvascular pericytes exhibit multipotential stem cell activity. J Cereb Blood Flow Metab 2006; 26: 613-624.

6 Oikawa H, Hayashi K, Maesawa C, et al. Expression profiles of nestin in vascular smooth muscle cells in vivo and in vitro. Exp Cell Res 2010; 316: 940-950.

7 Jiang MH, Cai B, Tuo Y, et al. Characterization of Nestin-positive stem Leydig cells as a potential source for the treatment of testicular Leydig cell dysfunction. Cell Res 2014; 24: 1466-1485.

8 Firth AL, Yuan JX. Identification of functional progenitor cells in the pulmonary vasculature. Pulm Circ 2012; 2: $84-100$. 
Pugliese SC, Poth JM, Fini MA, et al. The role of inflammation in hypoxic pulmonary hypertension: from cellular mechanisms to clinical phenotypes. Am J Physiol Lung Cell Mol Physiol 2015; 308: L229-L252.

10 Saboor F, Berndt C, Weissmann N, et al. Nestin expressing progenitor cells in pulmonary vasculature. Eur Respir J 2011; 38: Suppl. 55, 3342 .

11 Chabot A, Meus MA, Naud P, et al. Nestin is a marker of lung remodeling secondary to myocardial infarction and type I diabetes in the rat. J Cell Physiol 2015; 230: 170-179.

12 Birbrair A, Zhang T, Files DC, et al. Type-1 pericytes accumulate after tissue injury and produce collagen in an organ-dependent manner. Stem Cell Res Ther 2014; 5: 122.

13 Galie N, Torbicki A, Barst R, et al. Guidelines on diagnosis and treatment of pulmonary arterial hypertension. The Task Force on Diagnosis and Treatment of Pulmonary Arterial Hypertension of the European Society of Cardiology. Eur Heart J 2004; 25: 2243-2278.

14 Humbert M, Morrell NW, Archer SL, et al. Cellular and molecular pathobiology of pulmonary arterial hypertension. J Am Coll Cardiol 2004; 43: 12 Suppl. S, 13S-24S.

15 Yu L, Hales CA. Hypoxia does neither stimulate pulmonary artery endothelial cell proliferation in mice and rats with pulmonary hypertension and vascular remodeling nor in human pulmonary artery endothelial cells. $J$ Vasc Res 2011; 48: 465-475.

16 Schermuly RT, Ghofrani HA, Wilkins MR, et al. Mechanisms of disease: pulmonary arterial hypertension. Nat Rev Cardiol 2011; 8: 443-455.

17 Mignone JL, Kukekov V, Chiang AS, et al. Neural stem and progenitor cells in nestin-GFP transgenic mice. J Comp Neurol 2004; 469: 311-324.

18 Weissmann N, Nollen M, Gerigk B, et al. Downregulation of hypoxic vasoconstriction by chronic hypoxia in rabbits: effects of nitric oxide. Am J Physiol Heart Circ Physiol 2003; 284: H931-H938.

19 Schermuly RT, Dony E, Ghofrani HA, et al. Reversal of experimental pulmonary hypertension by PDGF inhibition. J Clin Invest 2005; 115: 2811-2821.

20 Wilson DW, Segall HJ, Pan LC, et al. Mechanisms and pathology of monocrotaline pulmonary toxicity. Crit Rev Toxicol 1992; 22: 307-325.

21 Abe K, Toba M, Alzoubi A, et al. Formation of plexiform lesions in experimental severe pulmonary arterial hypertension. Circulation 2010; 121: 2747-2754.

22 Pietra GG, Capron F, Stewart S, et al. Pathologic assessment of vasculopathies in pulmonary hypertension. $J$ Am Coll Cardiol 2004; 43: 12 Suppl. S, 25S-32S.

23 Owens GK. Regulation of differentiation of vascular smooth muscle cells. Physiol Rev 1995; 75: 487-517.

24 Sobue K, Hayashi K, Nishida W. Expressional regulation of smooth muscle cell-specific genes in association with phenotypic modulation. Mol Cell Biochem 1999; 190: 105-118.

25 Chung K, Wallace J, Kim SY, et al. Structural and molecular interrogation of intact biological systems. Nature 2013; 497: 332-337.

26 Muto A, Fitzgerald TN, Pimiento JM, et al. Smooth muscle cell signal transduction: implications of vascular biology for vascular surgeons. J Vasc Surg 2007; 45: Suppl. A, A15-A24.

27 Nguyen AT, Gomez D, Bell RD, et al. Smooth muscle cell plasticity: fact or fiction? Circ Res 2013; 112: 17-22.

28 Lacolley P, Regnault V, Nicoletti A, et al. The vascular smooth muscle cell in arterial pathology: a cell that can take on multiple roles. Cardiovasc Res 2012; 95: 194-204.

29 Paddenberg R, Stieger P, von Lilien AL, et al. Rapamycin attenuates hypoxia-induced pulmonary vascular remodeling and right ventricular hypertrophy in mice. Respir Res 2007; 8: 15.

30 Christen T, Verin V, Bochaton-Piallat M, et al. Mechanisms of neointima formation and remodeling in the porcine coronary artery. Circulation 2001; 103: 882-888.

31 Owens GK, Kumar MS, Wamhoff BR. Molecular regulation of vascular smooth muscle cell differentiation in development and disease. Physiol Rev 2004; 84: 767-801.

32 Wei LC, Shi M, Cao R, et al. Nestin small interfering RNA (siRNA) reduces cell growth in cultured astrocytoma cells. Brain Res 2008; 1196: 103-112.

33 Cui Y, Xiao Z, Han J, et al. MiR-125b orchestrates cell proliferation, differentiation and migration in neural stem/ progenitor cells by targeting Nestin. BMC Neurosci 2012; 13: 116.

34 Steinert PM, Chou YH, Prahlad V, et al. A high molecular weight intermediate filament-associated protein in BHK-21 cells is nestin, a type VI intermediate filament protein. Limited co-assembly in vitro to form heteropolymers with type III vimentin and type IV alpha-internexin. J Biol Chem 1999; 274: 9881-9890.

35 Vaittinen S, Lukka R, Sahlgren C, et al. The expression of intermediate filament protein nestin as related to vimentin and desmin in regenerating skeletal muscle. J Neuropathol Exp Neurol 2001; 60: 588-597.

36 Huang YL, Wu CM, Shi GY, et al. Nestin serves as a prosurvival determinant that is linked to the cytoprotective effect of epidermal growth factor in rat vascular smooth muscle cells. J Biochem 2009; 146: 307-315.

37 Park D, Xiang AP, Mao FF, et al. Nestin is required for the proper self-renewal of neural stem cells. Stem Cells 2010; 28: 2162-2171.

38 Klein D, Meissner N, Kleff V, et al. Nestin(+) tissue-resident multipotent stem cells contribute to tumor progression by differentiating into pericytes and smooth muscle cells resulting in blood vessel remodeling. Front Oncol 2014; 4: 169.

39 Rowley JE, Johnson JR. Pericytes in chronic lung disease. Int Arch Allergy Immunol 2014; 164: 178-188

40 Tang Z, Wang A, Yuan F, et al. Differentiation of multipotent vascular stem cells contributes to vascular diseases. Nat Commun 2012; 3: 875 .

41 Pitsiou G, Papakosta D, Bouros D. Pulmonary hypertension in idiopathic pulmonary fibrosis: a review. Respiration 2011; 82: 294-304.

42 Ehrmann J, Kolar Z, Mokry J. Nestin as a diagnostic and prognostic marker: immunohistochemical analysis of its expression in different tumours. J Clin Pathol 2005; 58: 222-223.

43 Ryuge S, Sato Y, Wang GQ, et al. Prognostic significance of nestin expression in resected non-small cell lung cancer. Chest 2011; 139: 862-869. 